\title{
Oxadiazole Based Polyether as Sensitive Films for Ratiometric Optical Temperature Detection
}

\author{
H. C. Neitzert, ${ }^{1}$ S. Cuccurullo, ${ }^{1}$ S. Concilio, ${ }^{1}$ and P. Iannelli ${ }^{2}$ \\ ${ }^{1}$ Dipartimento di Ingegneria Industriale (DIIn), Salerno University, Via Giovanni Paolo II 132, 84084 Fisciano, Italy \\ ${ }^{2}$ Dipartimento di Farmacia (DIFARMA), Salerno University, Via Giovanni Paolo II 132, 84084 Fisciano, Italy \\ Correspondence should be addressed to H. C. Neitzert; neitzert@unisa.it
}

Received 6 September 2016; Revised 17 October 2016; Accepted 19 October 2016

Academic Editor: Eugenio Martinelli

Copyright (C) 2016 H. C. Neitzert et al. This is an open access article distributed under the Creative Commons Attribution License, which permits unrestricted use, distribution, and reproduction in any medium, provided the original work is properly cited.

\begin{abstract}
A new type of polymer, based on the oxadiazole group, has been tested as indicator material for a ratiometric photoluminescence and optical reflection based temperature sensor in the temperature range between $30^{\circ} \mathrm{C}$ and $60^{\circ} \mathrm{C}$. Thin films of the new polymer have been deposited by spin-coating on a glass substrate, excited by means of a low-cost near UV-LED. The optical spectrum, as detected by a fiber-based PC-card optical spectrometer, consisted of the reflection peak at the excitation wavelength and two distinct photoluminescence peaks at $430 \mathrm{~nm}$ and $480 \mathrm{~nm}$, both in the blue spectral region. The peak amplitudes of all three spectral peaks depend linearly on the exciting light intensity. Changing the sample temperature, all peak amplitude values decrease monotonously with increasing temperature. By using a ratiometric approach, it has been found that the ratio between the two photoluminescence peaks was almost constant with temperature, while the ratio between the main photoluminescence peak at $430 \mathrm{~nm}$ and the reflection peak around $380 \mathrm{~nm}$ scaled nicely with the ambient temperature. Therefore, it has been proposed to use the latter criterion and a simple polynomial fit to the temperature versus peak amplitude relation.
\end{abstract}

\section{Introduction}

Temperature sensing is one of the most classical sensor domains. Despite the availability of excellent integrated silicon solutions with good linearity and sensitivity over a large temperature range there is even in this field a lot of research going on [1-3]. For example, the compensation of mechanical stress in silicon bandgap reference sensors has been shown to improve the performance of these types of sensors [4]. Nevertheless, there is a continuing interest in novel solutions for temperature sensors due to particular measurement conditions. For harsh environments as in space, for example, Ruthenium based thin film resistors have been shown to withstand rather high irradiation doses [5]. As another example in semiconductor growth environments, the substrates that are used for deposition can often not be in intimate contact with conventional sensors. On the other hand, the substrate temperature is often the most important parameter for semiconductor film growth [6] and the quality of interfaces in heterojunctions with extreme interest, for example, for high efficiency silicon based [7] or polymer type solar cells [8]. Therefore, a variety of noncontact temperature sensor solutions have been developed, based, for example, on emission corrected pyranometry [9] or diffuse reflectance spectroscopy [10]. Optical measurements give additionally the possibility to follow on a very short time scale the temperature evolution in materials and devices. For example, during the application of short ESD pulses to semiconductor lasers, the immediate temperature rise results in fast suppression of the optical emission of vertical cavity surface emitting lasers (VCSELs) [11] and can after opportune calibration be used to monitor the fast temperature transient during ESD pulse application. Optical temperature sensors, based on band-edge shifts, enable also the easy realization of optical fiber-based solutions that permit measuring the temperature in remote location [12].

Another important research field, where conventional sensors are difficult to use, is biology. Therefore, in biological environments, optical temperature sensing techniques are strongly favored. In this case, only a limited temperature range is of interest, but stability in an aggressive environment and biocompatibility are required. Sensitive in vitro and 


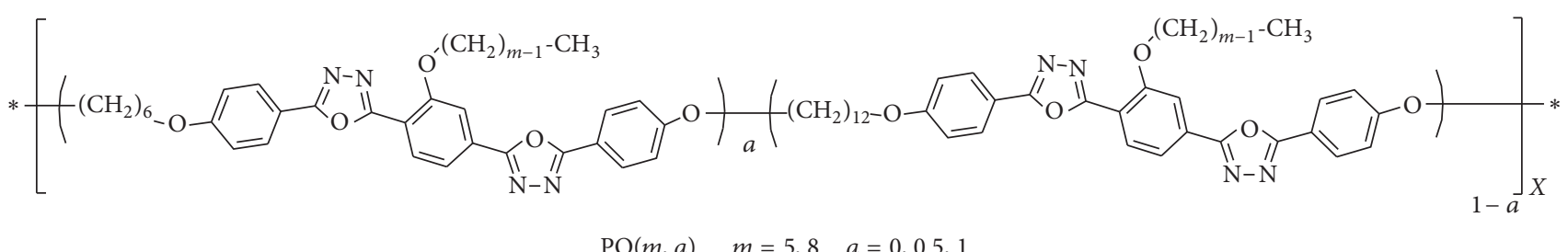

Scheme 1: Structure of the oxadiazole based polymer (in our case: $m=8$ and $a=0.5$ ).

in vivo measurements have, for example, been achieved by using a dual emissive phosphorescent polymeric thermometer that incorporates two long-lived phosphorescent iridium complexes into an acrylamide-based thermosensitive polymer [13]. In this case, even intracellular temperature measurements have been reported. In addition, fluorescence spectroscopy, using a green fluorescent protein as thermal nanoprobe, has been shown to enable intracellular noninvasive temperature monitoring [14]. While often nonbiological materials are used as markers in biological applications, recently it has also been shown that biological cells from Candida can be used together with multiwalled carbon nanotubes to form a stable tissue that has excellent temperature sensing properties in a wide temperature range up to $373 \mathrm{~K}$ as a simple resistance thermometer [15].

Here we want to show the possibility to use a new type of polymer [16], based on the oxadiazole group for the realization of a photoluminescence (PL) based temperature sensor, and discuss the most stable readout configuration. In literature [13] it is, for example, reported that, for some materials with multiple peak emission, the ratio between different emission peak amplitudes is a good measure for the sample temperature. This is checked in the case of the proposed oxadiazole based polymer and compared to different ratiometric criteria.

\section{Sample Structure and Preparation}

The synthesis and the structural characterization of the segmented polyesters (PO), containing the oxadiazole unit, have been reported elsewhere [16]. The general structure of the synthesized polymer is shown in Scheme 1. The insertion of the flexible aliphatic segments along and aside the chain reduces the melting temperature and improves the solubility in organic solvents, while promoting the appearing of the nematic phase. In our specific case the copolymer with $m=8$ and $a=0.5$ has been used. An inherent viscosity value of $0.39 \mathrm{dL} / \mathrm{g}$ at $25^{\circ} \mathrm{C}$ has been measured for this copolymer, using an Ubbelohde viscometer. The viscosity measurements were performed in $0.5 \mathrm{~g} / \mathrm{dL}$ chloroform $+5 \%$ trifluoroacetic acid solutions. The good solubility in chlorinate solvents allows the preparation of films with homogeneous thickness by spinning technique and the glass transition temperature in the range $100-120^{\circ} \mathrm{C}$ ensures good stability of the film morphology at room temperature and above. All these features make PO suitable as active material in the fabrication of electronic devices, such as polymer LEDs [17] and low-voltage electronic memories [18]. Oxadiazole embedded in polyurethane [19] or in combination with polyazothines [20] has also been reported to be applicable as electrical switching device.

It should be mentioned that already early reports on oxadiazole based polymers as electroluminescent devices [21, 22] report strong emission in the blue wavelength range and also a relatively stable behavior even under normal ambient conditions $[23,24]$. Another particular interesting feature of these polymers is the low overlap of emission and absorption spectra, so that the reabsorption is minimized [24], which results in a high overall efficiency, when using this type of polymer as active layer in LEDs [25].

It should also be mentioned that oxadiazole groups with their excellent electron conducting properties are not only used in polymerized form. Also small molecules based blue emitting organic LEDs and heterojunction diodes with oxadiazole units in combination with carbazole units have been reported [26, 27].

The investigated samples were then realized by the deposition by spin-coating on top of a glass substrate. The thickness of the polymer film, obtained with the used spinning conditions, was about $90 \mathrm{~nm}$ with a surface roughness of about $4 \mathrm{~nm}$. The film thickness has been determined by atomic force microscope (AFM) imaging of the films, deposited on the glass substrate and cut with a razor blade.

\section{Measurement Setup}

The setup for temperature dependent photoluminescence measurements is schematically shown in Figure 1. A near UV-LED with integrated glass lens (nominal wavelength of $370 \mathrm{~nm}$ and a maximal optical power of $1 \mathrm{~mW}$ ) and a fiber coupled PC-based Ocean Optics "PC2000" spectrometer for the detection have been used. The optical geometry is optimized in a way that the exciting LED is mounted perpendicular to the investigated film, while the receiving optical fiber is positioned with a $45^{\circ}$ angle respective to the film surface. With this geometry it could be achieved that the signal height of the exciting UV light and the photoluminescence signal height are in the same order of magnitude for polymer films of about $90 \mathrm{~nm}$ thickness.

The temperature control has been realized with Peltier elements inserted between the dissipator and a thinner aluminum plate, which has been equipped with a calibrated NTC resistor as temperature sensor. The glass plate with the PO film has been tightly attached to the upper aluminum plate and thermally conducting paste has been used to achieve a good thermal contact between glass substrate and aluminum plate. The temperature control has been done using the PID 


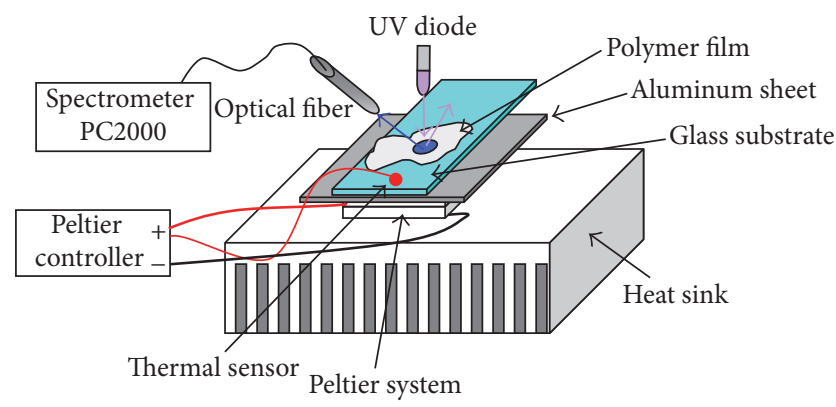

Figure 1: Temperature control system and optical measurement setup.

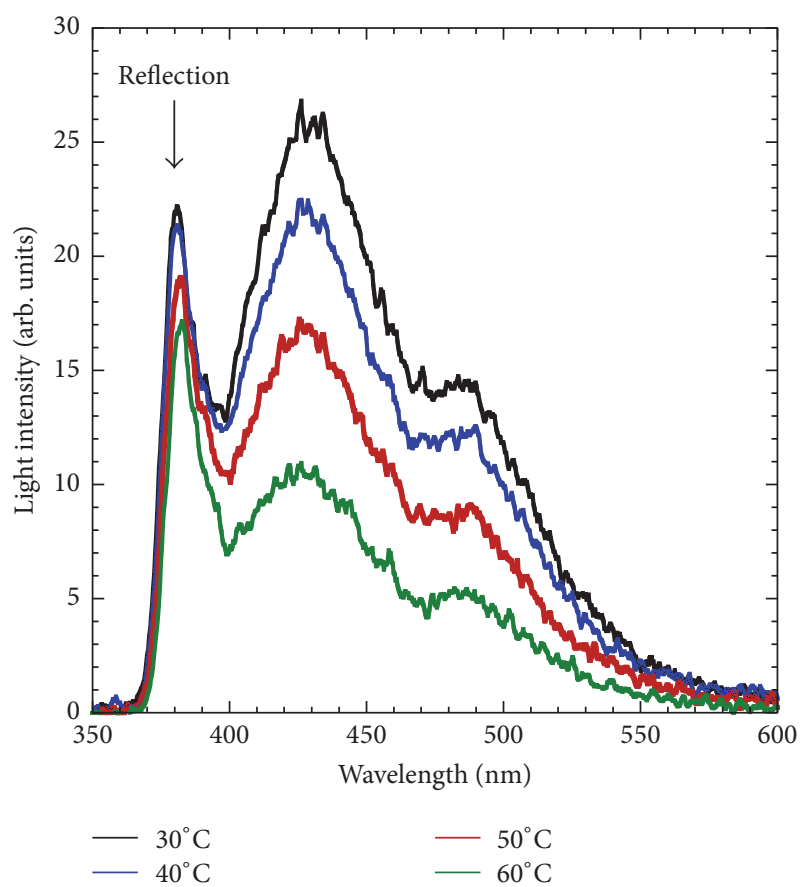

FIgURE 2: Sensor fiber light intensity spectra shown for 4 different film temperatures (the reflected light related peak is indicated by an arrow).

control section of a Melles-Griot DLD103 Laser controller with integrated temperature controller. Also the details of the thermal control setup are shown in Figure 1.

\section{Results and Discussions}

4.1. Optical Characterization. In Figure 2, typical photoluminescence spectra for spin-coating deposited polymer films with a UV-LED (nominally emitting at $370 \mathrm{~nm}$ and with an optical output power of $1 \mathrm{~mW}$ ) measured at 4 different temperatures between $30^{\circ} \mathrm{C}$ and $60^{\circ} \mathrm{C}$ are shown.

No optical filter has been used to suppress the UV light used for excitation so that in the optical spectra below $400 \mathrm{~nm}$ also a contribution of the UV light, reflected by the sample, is observed. The peak position of the reflected light has been found to be at $380 \mathrm{~nm}$, slightly higher than the nominal wavelength of the commercial LED. Besides the dominant luminescence peak at $430 \mathrm{~nm}$, a broad shoulder at a wavelength of $480 \mathrm{~nm}$ with a smaller peak amplitude can be seen. It should be mentioned that we found that the shape of the photoluminescence spectrum in a wide range does not depend on the exciting optical power value.

From the spectra, partially shown in Figure 2, we extracted the peak amplitudes for the PL emission peaks and additionally for the peak, related to the reflection of the exciting light. The temperature dependence of these amplitude values in a range between $30^{\circ} \mathrm{C}$ and $60^{\circ} \mathrm{C}$ is shown in Figure 3(a). A monotonic decrease of the amplitudes of all three optically revealed peaks with increasing temperature is found. For the PL peaks at $430 \mathrm{~nm}$ (first peak) and $480 \mathrm{~nm}$ (second peak) a smooth behavior has been found, while in the case of the reflection peak at $380 \mathrm{~nm}$ also a monotonic decrease but with ondulations and local maxima at $40^{\circ} \mathrm{C}$ and $55^{\circ} \mathrm{C}$ has been observed. This latter observation may be due to interference effects in the thin organic layer.

We checked also how the revealed optical peak amplitudes depend on the exciting light power. As can be seen in Figure 3(b), increasing the luminescence peak amplitude values (at $430 \mathrm{~nm}$ and $480 \mathrm{~nm}$ ) and also the UV reflectance peak amplitude value is strictly linear with increasing power of the UV-LED in the investigated power range up to $1 \mathrm{~mW}$.

In a next step we plotted the ratio of the $430 \mathrm{~nm}$ PL emission peak and the $480 \mathrm{~nm}$ PL emission peak as a function of the sample temperature (see Figure 4). No clear correlation between PL emission amplitude ratio and sample temperature is found. Between $30^{\circ} \mathrm{C}$ and $45^{\circ} \mathrm{C}$ the ratio is almost independent of the sample temperature and has a value of about 1.8, while at higher temperatures a nonmonotonic behavior is found. These findings show that the ratio between two PL peaks as often proposed in literature [13] cannot in our case be used for a ratiometric measurement of the sample temperature.

As an alternative ratiometric measure, we plotted in Figure 5 the ratio between the reflection peak amplitude and the first PL emission peak amplitude as a function of the substrate temperature. In this case we find a monotonic increase of the peak amplitude ratio with increasing temperature from a value of about 0.85 at $30^{\circ} \mathrm{C}$ up to a value of about 1.5 at $60^{\circ} \mathrm{C}$. The behavior can nicely be fitted (see fitting parameters in the inset) with a 2nd-order polynomial fit and the $R$ coefficient is higher than 0.99 , even if the abovementioned interference peaks at $40^{\circ} \mathrm{C}$ and $55^{\circ} \mathrm{C}$ are slightly visible also in this plot. Therefore it can be concluded that the peak amplitude of the PL emission itself is a good measure for the sample temperature (see Figure 2). By including the reflection peak amplitude, however, even a good ratiometric criterion for temperature measurements, using the oxadiazole based polyether, has been found.

4.2. Electrical Characterization. In order to determine the film conductivity, the current-voltage characteristics of a spin-coated film in a coplanar geometry with a gap of about $2 \mathrm{~mm}$ between the parallel contacts on the surface were measured. In Figure 6 we see the electrical current, measured during 3 thermal cycles between room temperature and $60^{\circ} \mathrm{C}$ with an applied voltage of $100 \mathrm{~V}$, where the temperature 


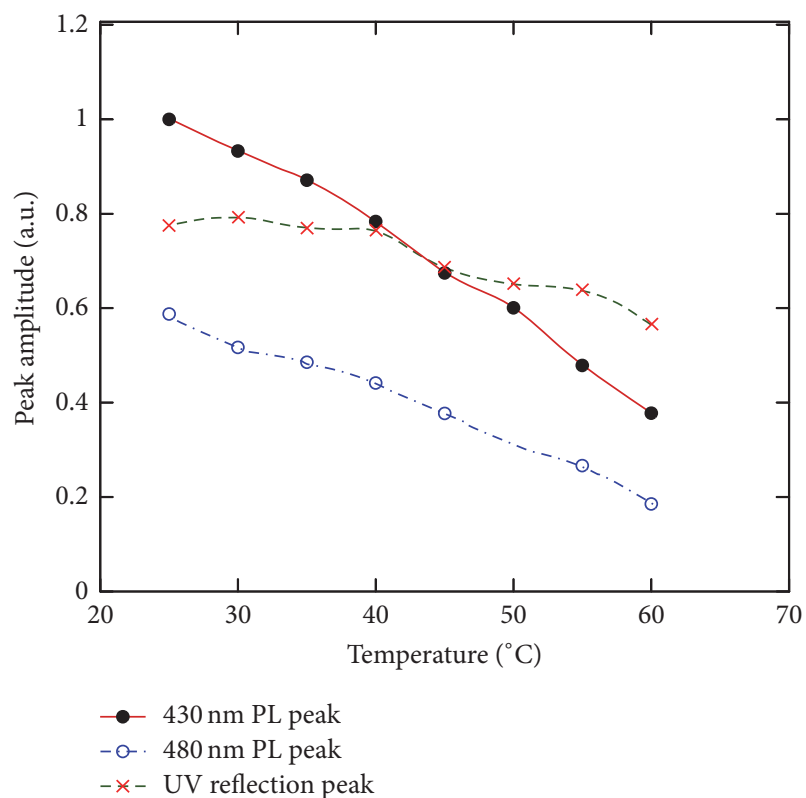

(a)

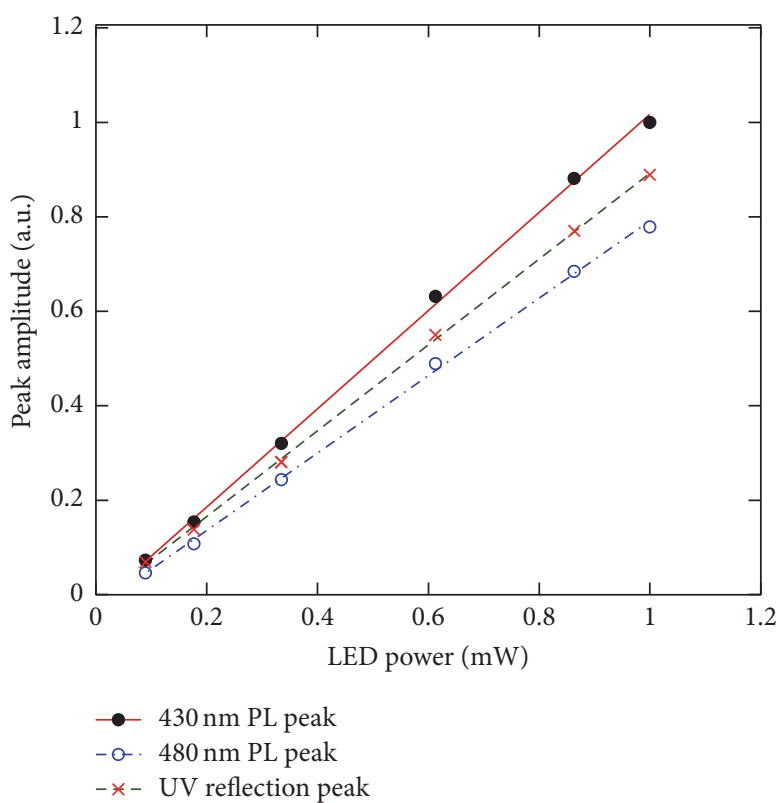

(b)

FIGURE 3: Dependence of the amplitudes of the reflection peak and of the 2 principal photoluminescence peaks (first peak at $430 \mathrm{~nm}$ and second peak at $480 \mathrm{~nm}$ ), (a) on the sample temperature (with an excitation LED power of $1 \mathrm{~mW}$ ) and (b) on the excitation LED power (at room temperature).

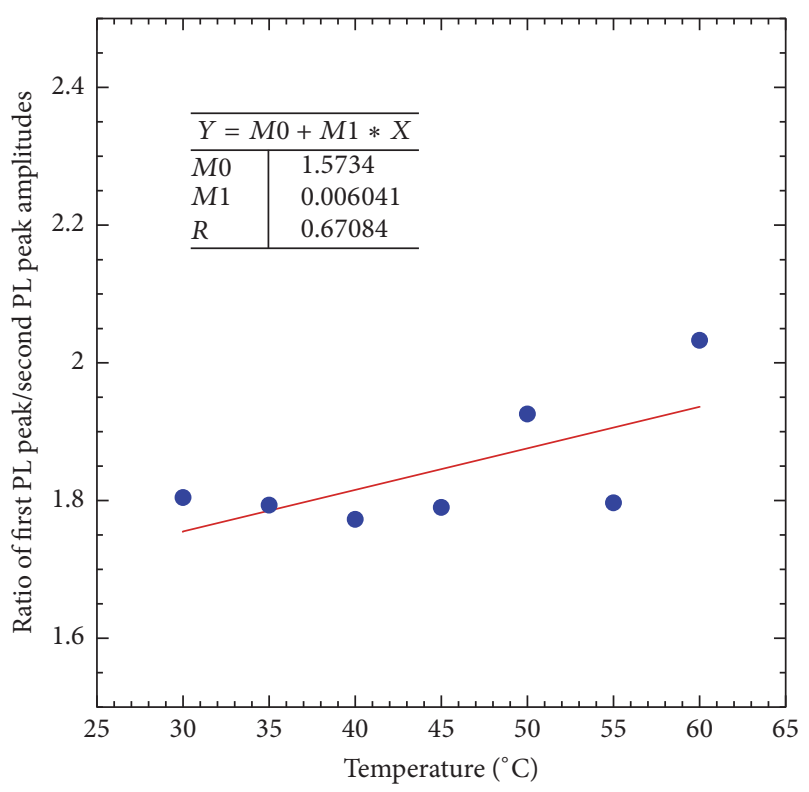

FIGURE 4: Ratio between the principal photoluminescence peaks with linear fit (the fitting parameters are shown as inset).

has been changed stepwise with steps of $5^{\circ} \mathrm{C}$ using the Peltier based temperature control system, which has been described above. The monitoring of the sample temperature with the NTC sensor (upper trace in Figure 6) shows the extremely good stability of the temperature control without any overshoot during the temperature changes. Regarding the development of the conductivity we observe directly

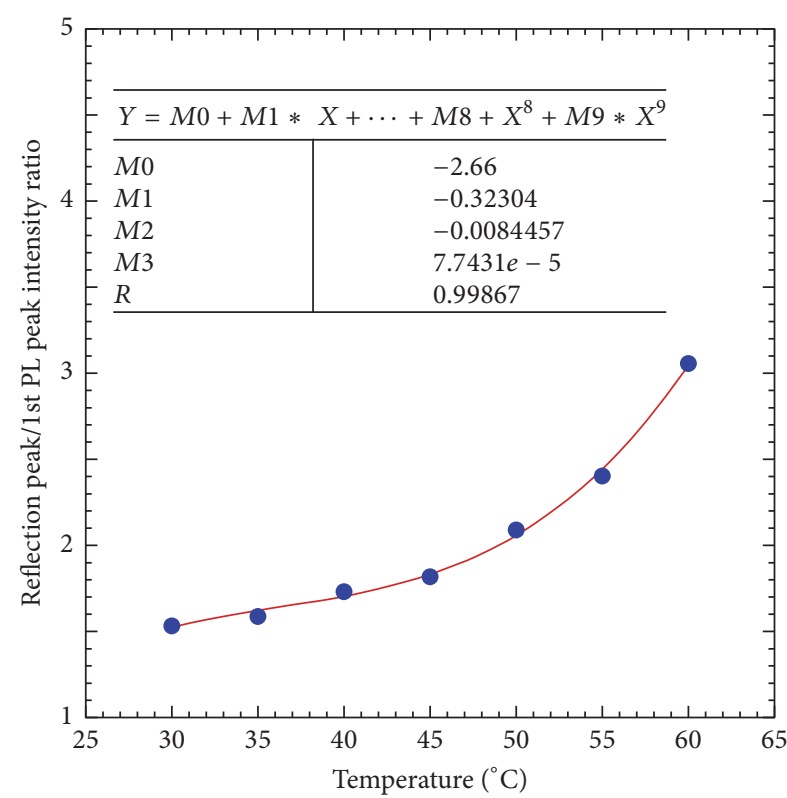

FIgURE 5: Ratio between the amplitude of the reflection peak and the amplitude of the principal photoluminescence peak at $430 \mathrm{~nm}$ as a function of the sample temperature with polynomial fit (red line) (the fit parameters are shown in the inset).

after applying the constant voltage at $25^{\circ} \mathrm{C}$ a rather instable current, which is strongly decreasing within the first minutes. Later on during the first cycle, the current remains relatively stable during the single temperature steps. This holds in 


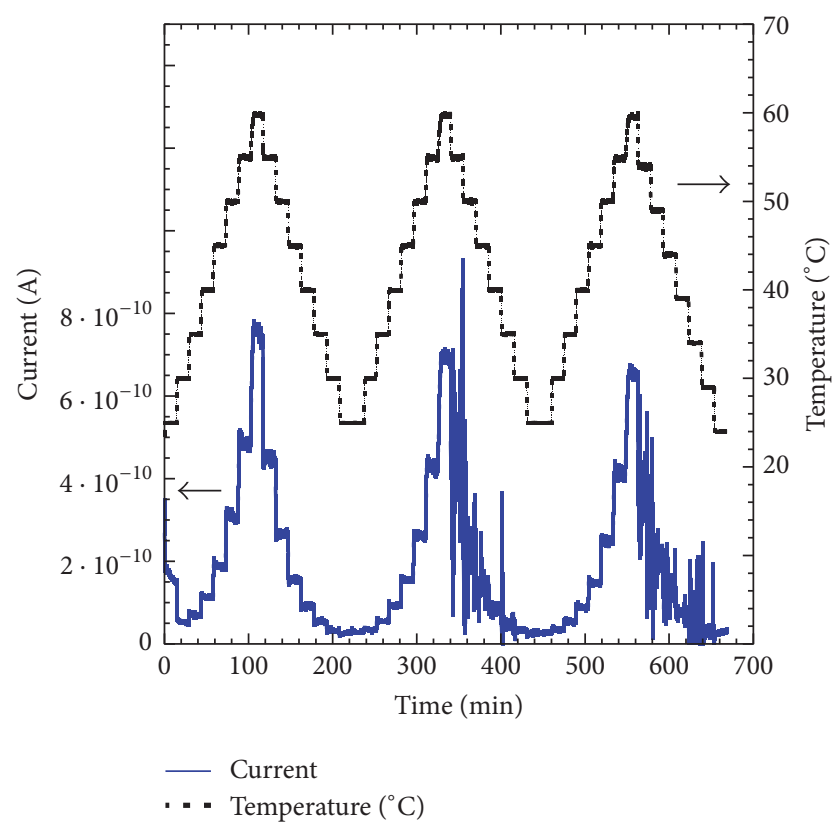

FIgURE 6: Current of the PO sample (in coplanar configuration with an applied voltage of $50 \mathrm{~V}$ ) during three subsequent temperature cycles.

particular for the decreasing temperature period. During the subsequent 2 temperature cycles we observe first of all a decrease of the current maxima values and additionally an extremely noisy behavior during the cooling periods. The results indicate that it is much more difficult to obtain stable electrical behavior of the investigated polymer than stable optical characteristics. This is a common feature to very different organic materials and also nanocomposite films. Nevertheless we want to demonstrate that electrical measurements can give valuable information about the polymer physics. Therefore we show in Figure 7 a zoom into the relatively stable first temperature cycle of the experiment, described above. In this case we restricted the temperature range to values between $30^{\circ} \mathrm{C}$ and $60^{\circ} \mathrm{C}$. An Arrhenius plot of the average current, measured during the heating and cooling cycle (see Figure 8), shows that the conduction process in that instant can be described by single activation energies in the whole investigated temperature range. By comparison of the 2 exponential fits for increasing and decreasing temperatures, we observe that the activation energy increases already slightly during the first temperature cycle. Looking at the temperature monitoring during this cycle, we observe even better than in Figure 6 the excellent temperature regulation properties of the Peltier based system.

\section{Conclusions}

A simple but very stable measurement setup has been realized for the temperature dependent optical and electrical characterization of a new, oxadiazole containing, electron conducting polymer with relevant applications as polymer LED and a low-voltage electrical bistable device. With the

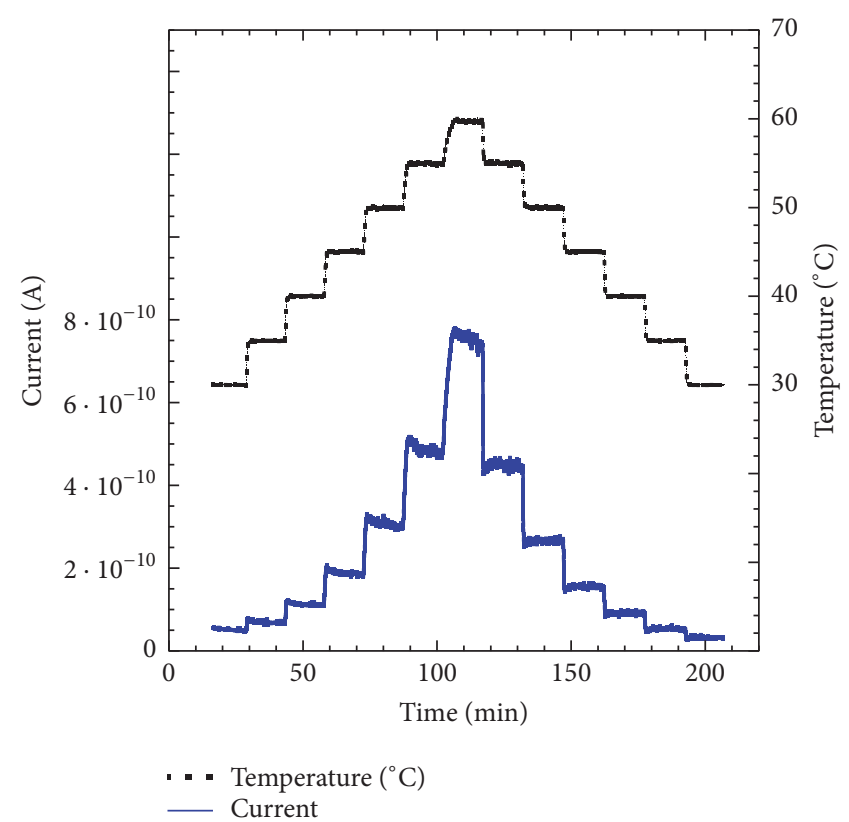

FIgURE 7: Current of the PO sample (in coplanar configuration with an applied voltage of $50 \mathrm{~V}$ ) during the first temperature cycle in the temperature range between $30^{\circ} \mathrm{C}$ and $60^{\circ} \mathrm{C}$ in steps of $5^{\circ} \mathrm{C}$.

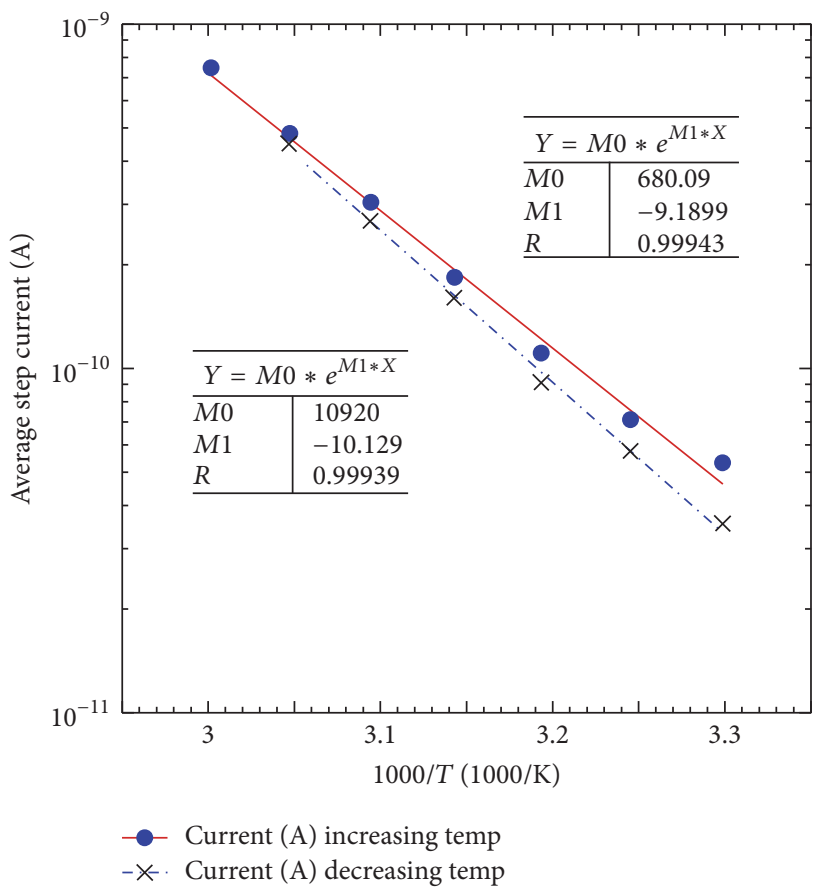

FIGURE 8: Arrhenius plot of the average currents of the PO sample, as determined at each temperature step between $30^{\circ} \mathrm{C}$ and $60^{\circ} \mathrm{C}$ during the first temperature cycle, separately plotted for the increasing temperature and the decreasing temperature part.

low-cost optical measurement system, three principal peaks have been measured on the spin-coating deposited polymer film. The first one is related to the exciting light reflection and the other two peaks are correlated with the blue light photoluminescence at $430 \mathrm{~nm}$ and at $480 \mathrm{~nm}$. It has been found that all three peak amplitudes decrease with 
increasing sample temperature. As best ratiometric based criterion, the ratio between the reflection peak and the most prominent photoluminescence peak has been found. In this case, a simple polynomial temperature-peak ratio relation has been observed. Additional electrical conductivity measurements in coplanar configuration during multiple temperature cycling have been performed, revealing an unstable longterm behavior, developing after the first, relatively stable, temperature cycle.

\section{Disclosure}

Present address of S. Cuccurullo is STMicroelectronics SRL, Via Defeo Remo 1, 80022 Arzano, Italy.

\section{Competing Interests}

The authors declare that there is no conflict of interests regarding the publication of this paper.

\section{Acknowledgments}

The authors want to thank Fulvia Villani from the ENEA Portici Research Laboratory for spin-coating deposition and AFM characterization of the polymer film.

\section{References}

[1] M. Mansoor, I. Haneef, S. Akhtar, A. De Luca, and F. Udrea, "Silicon diode temperature sensors-a review of applications," Sensors and Actuators A: Physical, vol. 232, pp. 63-74, 2015.

[2] G. C. M. Meijer, G. Wang, and F. Fruett, "Temperature sensors and voltage references implemented in CMOS technology," IEEE Sensors Journal, vol. 1, no. 3, pp. 225-234, 2001.

[3] M. Malits and Y. Nemirovsky, "Comprehensive comparison of integrated temperature sensors in CMOS-SOI technology," in Proceedings of the IEEE International Conference on Microwaves, Communications, Antennas and Electronic Systems (COMCAS '15), pp. 1-5, Tel-Aviv, Israel, November 2015.

[4] M. Motz, U. Ausserlechner, and M. Holliber, "Compensation of mechanical stress-induced drift of bandgap references with onchip stress sensor," IEEE Sensors Journal, vol. 15, no. 9, pp. 51155121, 2015.

[5] S. J. Ravelo Arias, D. Ramirez Munoz, S. Cardoso, and P. P. Freitas, "Ru-based thin film temperature sensor for space environments: microfabrication and characterization under total ionizing dose," Journal of Sensors, vol. 2016, Article ID 6086752, 5 pages, 2016.

[6] J. Ramanujam and A. Verma, "Photovoltaic properties of a-Si:H films grown by plasma enhanced chemical vapor deposition: a review," Materials Express, vol. 2, no. 3, pp. 177-196, 2012.

[7] A. Ulyashin, R. Bilyalov, A. Brueck, M. Scherff, R. Job, and J. Poortmans, "Minority carrier lifetime improvement in ptype silicon by oxygen related centers gettering at low temperatures: application to the heterojunction solar cell processing," in Proceedings of the 3rd Conference on Photovoltaic Energy Conversion, pp. 1088-1091, Osaka, Japan, May 2003.

[8] C. Barone, G. Landi, A. De Sio, H. C. Neitzert, and S. Pagano, "Thermal ageing of bulk heterojunction polymer solar cells investigated by electric noise analysis," Solar Energy Materials and Solar Cells, vol. 122, pp. 40-45, 2014.

[9] K. Haberland, J. T. Mullins, T. Schenk et al., "First real-time true wafer temperature and growth rate measurements in a closed-coupled showerhead movpe reactor during growth of InGa(AsP)," in Proceedings of the International Conference on Indium Phosphide and Related Materials, pp. 44-47, Santa Barbara, Calif, USA, May 2003.

[10] R. Gu, C. Shen, Y. Guo, W. Wang, X. Fu, and L. Chen, "In situ thickness and temperature measurements of CdTe grown by molecular beam epitaxy on GaAs substrate," Journal of Vacuum Science and Technology B:Nanotechnology and Microelectronics, vol. 30, no. 4, Article ID 041203, 2012.

[11] H.-C. Neitzert, B. Gobbi, and A. Piccirillo, "Sensitivity of proton implanted VCSELs to electrostatic discharge pulses," IEEE Journal on Selected Topics in Quantum Electronics, vol. 7, no. 2, pp. 231-241, 2001

[12] S. Torres-Peiro, A. Diez, J. L. Cruz, and M. V. Andres, “Temperature sensor based on Ge-doped microstructured fibers," Journal of Sensors, vol. 2016, Article ID 417540, 5 pages, 2016.

[13] Z. Chen, K. Y. Zhang, X. Tong et al., "Phosphorescent polymeric thermometers for in vitro and in vivo temperature sensing with minimized background interference," Advanced Functional Materials, vol. 26, no. 24, pp. 4386-4396, 2016.

[14] J. S. Donner, S. A. Thompson, M. P. Kreuzer, G. Baffou, and R. Quidant, "Mapping intracellular temperature using green fluorescent protein," Nano Letters, vol. 12, no. 4, pp. 2107-2111, 2012.

[15] R. Di Giacomo, B. Maresca, A. Porta, P. Sabatino, G. Carapella, and H.-C. Neitzert, "Candida albicans/MWCNTs: a stable conductive bio-nanocomposite and its temperature-sensing properties," IEEE Transactions on Nanotechnology, vol. 12, no. 2, pp. 111-114, 2013.

[16] D. Acierno, E. Amendola, S. Bellone et al., "Synthesis and characterization of a new class of nematic photoluminescent oxadiazole-containing polyethers," Macromolecules, vol. 36, no. 17, pp. 6410-6415, 2003.

[17] H.-C. Neitzert, S. Concilio, P. Iannelli, and P. Vacca, "Electronic memory effect in a crystalline silicon/polyether heterostructure," Physica Status Solidi (C), vol. 7, no. 3-4, pp. 988-991, 2010.

[18] D. Acierno, E. Amendola, S. Bellone et al., "Synthesis and luminescent properties of a new class of nematic oxadiazole containing poly-ethers for PLED," Journal of Non-Crystalline Solids, vol. 338-340, no. 1, pp. 278-282, 2004.

[19] Y. Sun, L. Li, D. Wen, and X. Bai, "Bistable electrical switching characteristics and memory effect by mixing of oxadiazole in polyurethane layer," The Journal of Physical Chemistry C, vol. 119, no. 33, pp. 19520-19525, 2015.

[20] L. Pan, B. Hu, X. Zhu et al., "Role of oxadiazole moiety in different $\mathrm{D}-\mathrm{A}$ polyazothines and related resistive switching properties," Journal of Materials Chemistry C, vol. 1, no. 30, pp. 4556-4564, 2013.

[21] N. Tamoto, C. Adachi, and K. Nagai, "Electroluminescence of 1,3,4-oxadiazole and triphenylamine-containing molecules as an emitter in organic multilayer light emitting diodes," Chemistry of Materials, vol. 9, no. 5, pp. 1077-1085, 1997.

[22] Z. Peng, Z. Bao, and M. E. Galvin, "Oxadiazole-containing conjugated polymers for light-emitting diodes," Advanced Materials, vol. 10, no. 9, pp. 680-684, 1998.

[23] R.-T. Chen, S.-H. Chen, B.-Y. Hsieh, and Y. Chen, "Synthesis, photophysics, and electroluminescent performance of 
stable blue-light-emitting copoly(9,9-diarylfluorene)s," Journal of Polymer Science, Part A: Polymer Chemistry, vol. 47, no. 11, pp. 2821-2834, 2009.

[24] M. K. Huda and S. K. Dolui, "Luminescence property of poly(1,3-bis(phenyl-1,3,4-oxadiazole))s containing polar groups in the main chain," Journal of Luminescence, vol. 130, no. 11, pp. 2242-2246, 2010.

[25] Z. Peng and J. Zhang, "Novel oxadiazole-containing conjugated polymers as efficient single-layer light-emitting diodes," Synthetic Metals, vol. 105, no. 1, pp. 73-78, 1999.

[26] H. C. Neitzert, M. Ferrara, A. Rubino et al., "Monitoring of the initial degradation of oxadiazole based blue OLED's," Journal of Non-Crystalline Solids, vol. 352, no. 9-20, pp. 1695-1699, 2006.

[27] S. Concilio, V. Bugatti, H. C. Neitzert et al., "Zn-complex based on oxadiazole/carbazole structure: synthesis, optical and electric properties," Thin Solid Films, vol. 556, pp. 419-424, 2014. 


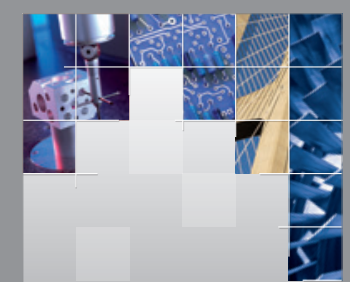

\section{Enfincering}
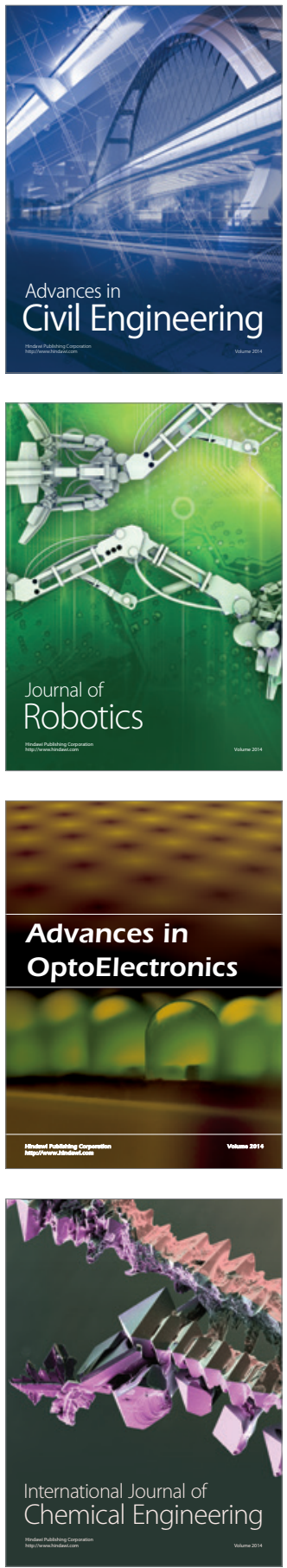

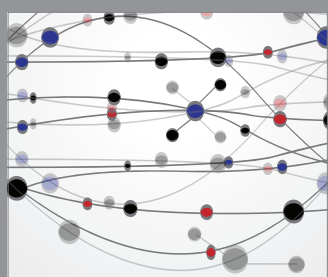

The Scientific World Journal

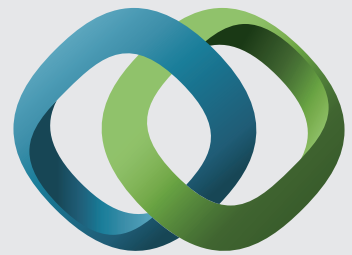

\section{Hindawi}

Submit your manuscripts at

http://www.hindawi.com
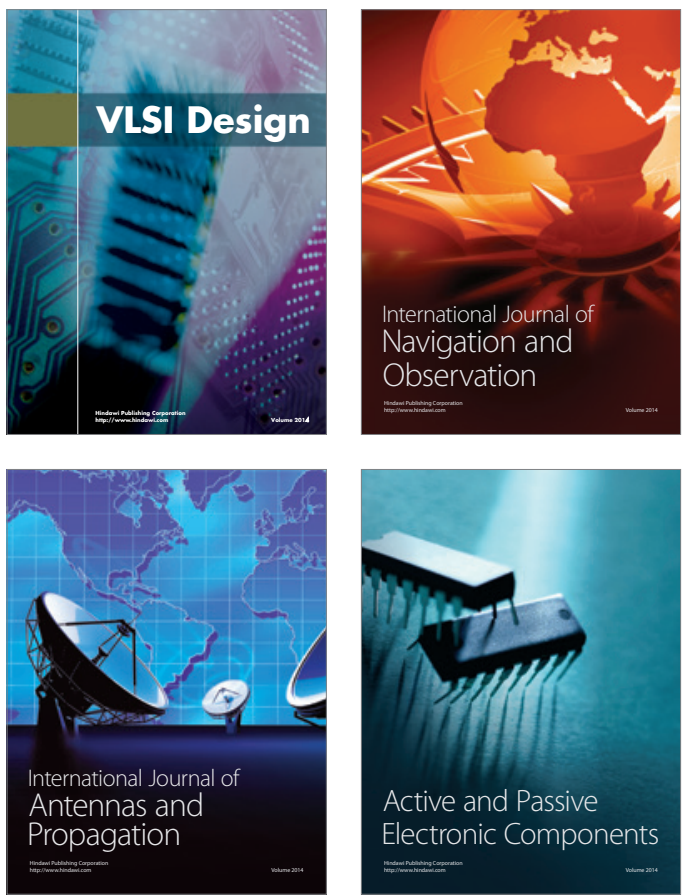
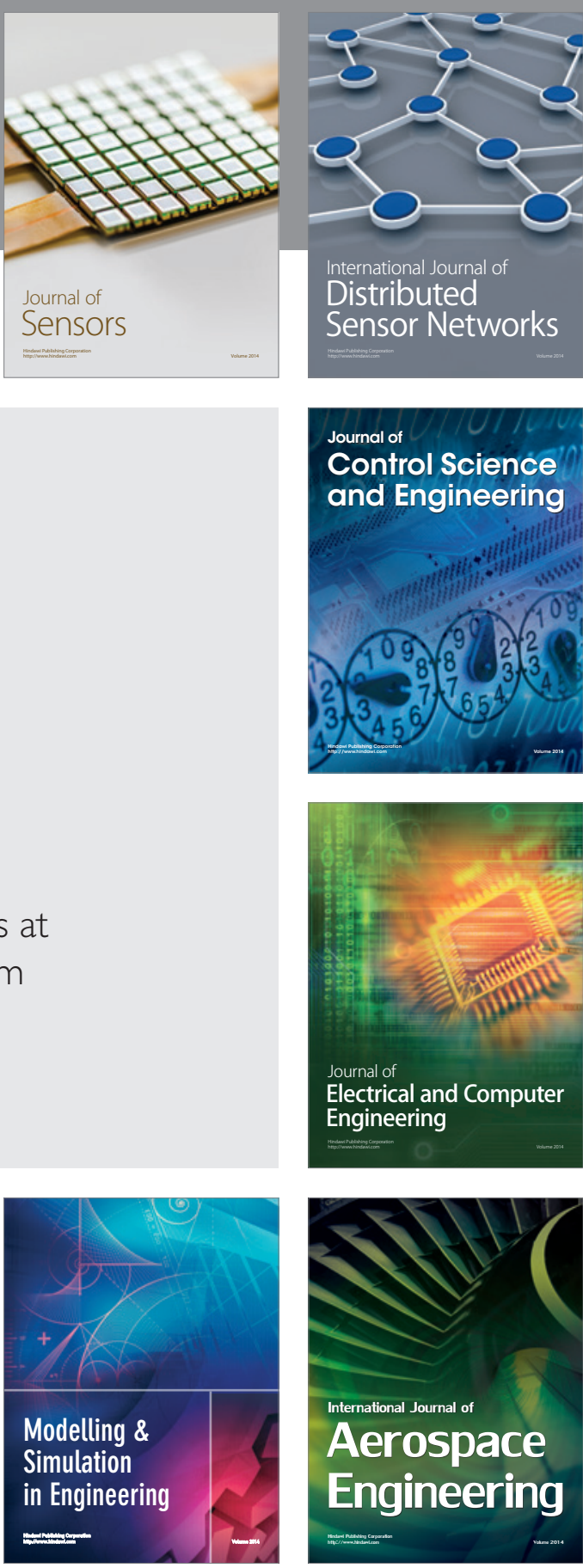

International Journal of

Distributed

Sensor Networks

Journal of

Control Science

and Engineering
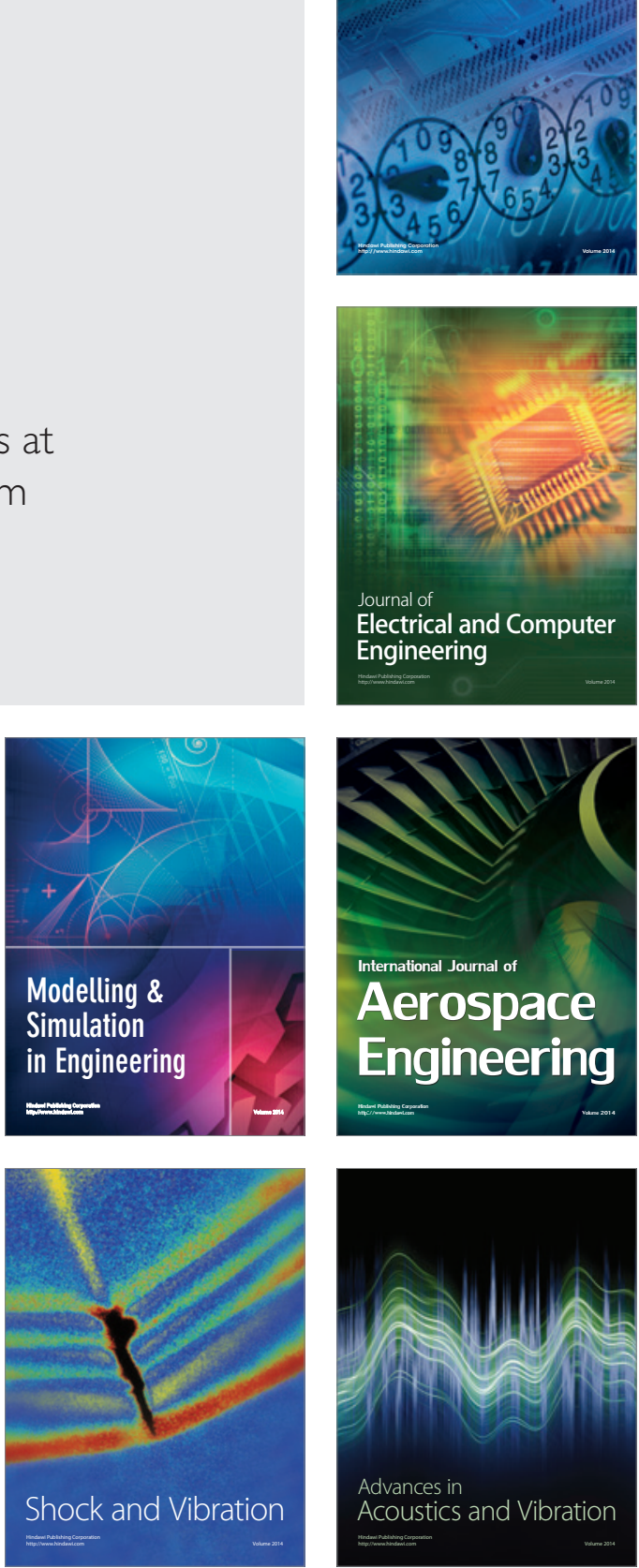